\title{
STEREOLOGICAL EVIDENCE FOR DE/RE-GENERATION OF MYELIN SHEATHS IN AGED BRAIN WHITE MATTER OF FEMALE RATS
}

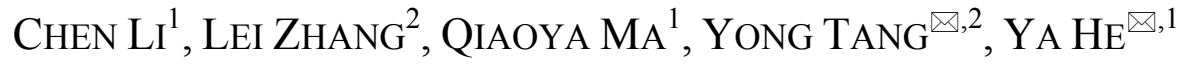 \\ ${ }^{1}$ Department of Geriatrics Neurology, The Second Affiliated Hospital of Xi' an Jiaotong University, Xi'an \\ Jiaotong University, Xi'an, P. R. China; ${ }^{2}$ Department of Histology and Embryology, Chongqing Medical \\ University, Chongqing, P. R. China. \\ e-mail: 18629647763@163.com; 351517366@qq.com,dd_mm2012@163.com; ytang062@163.com, \\ hesu2011@sina.com \\ (Received November 15, 2015; revised April 16, 2017; accepted April 26, 2017)
}

\begin{abstract}
Studies have provided qualitative evidence of de-myelination and re-myelination in aged brain white matter. However, there have been no quantitative evidences of degeneration and regeneration of myelin sheaths in white matter. The present study was designed to investigate the quantitative changes in myelin sheaths using unbiased stereological techniques and qualitative changes using electron microscopy in aged brain white matter. Results obtained showed that in brain white matter, the total volume of myelin sheaths of old-age female rats was not significantly different from that of young female rats, but the total length of myelinated fibers in old female rats was significantly decreased by $46.1 \%$ when compared with that of young female rats. Myelin sheath volume per unit length of myelinated fibers of old female rats was significantly increased by $43.4 \%$ compared with that of young female rats. The mean thickness of myelin sheaths in the white matter of the old rats was significantly increased by $33.3 \%$, when compared with that of young female rats. In age-related loss of myelinated fibers, most fibers had diameters less than $1.4 \mu \mathrm{m}$, and myelin sheath thicknesses less than $0.14 \mu \mathrm{m}$, but the length of myelinated fibers with diameters more than $0.6 \mu \mathrm{m}$ and myelin sheath thicknesses more than $0.22 \mu \mathrm{m}$ increased with age. Myelinated fibers with ratios of myelin sheath thicknesses to myelinated fiber external diameter less than 0.21 were significantly lower in elderly rats than in young rats. However, the total length of myelinated fibers with ratios of myelin sheath thicknesses to myelinated fiber external diameter more than 0.23 was higher in aged rats than in young rats. About $6.58 \%$ of myelin sheaths showed degenerative alterations, while $0.88 \%$ myelin sheaths showed regenerative alterations. This study provides stereological evidence not only for degeneration but also regeneration of myelin sheaths in aged white matter.
\end{abstract}

Keywords: aging, de/re-myelination, myelin sheath, stereology, white matter

\section{INTRODUCTION}

Stereological methods of assessment have shown that the main structural changes in aged brain are atrophy of the white matter (Pakkenberg \& Gundersen, 1997). In addition, MRI assessment has revealed that agerelated loss of white matter is more significant than that of gray matter (Guttmann et al., 1998; Jernigan et al., 2001). Recent studies using Diffusion Tensor Imaging (DTI) reported that white matter was connected to cognitive functions, and ultrastructural changes in the integrity of white matter were very responsive to cognitive changes during aging (Del Bigio et al., 2003; Nagy et al., 2004; Shenkin et al., 2005; Huang and Auchus, 2007). Since the integrity of white matter tract relies mostly on the integrity of myelin sheaths, it can be inferred that myelin sheaths integrity is sensitive to aging.
Kemper (1994) reported that the staining of white matter in the brains of aged primates was paler than that in young primates. Peters and his team also made a long term observation of myelin sheath degenerations in various areas of aged monkey brains, mainly the anterior commissure, primary visual and corpus callosum (Peters et al., 2000; 2001; Peters and Sethares, 2002; Sandell and Peters, 2003). These previous studies suggest that a clear trend to the effect that the number of monkey primary visual cortex oligodendrocytes increases with increase in years (Peters et al., 1991; Peters, 1996). These observations show that oligodendrocytes proliferate during the aging process. This raises the question about the relevance of additional oligoendrocytes during aging.

Thus, qualitative evidence of re-myelination in different regions of aged monkey have been extensively investigated (Peters et al., 2000; 2001; Peters and 
Sethares, 2003). Unlike the regular distribution of fibers in regions such as anterior commissure and corpus callosum, myelinated fibers were randomly distributed in other regions of white matter, which contributed to difficulty in locating myelin sheaths in myelinated fibers.

Since 1984, new design-based stereological methods have been developed, which allow for unbiased estimates of structures (Sterio, 1984; Gundersen et al., 1988a, b; Moller et al., 1990; Li et al., 2009). However, comprehensive literature search revealed no such reports on myelin sheaths of aged rats. This study used an unbiased estimation method based on stereological principles to estimate myelin sheaths in aged rat white matter, with transmission electron microscopy and modern stereological techniques.

\section{MATERIAL AND METHODS}

\section{ANIMALS}

Six young (6-8 months old) and nine old (27-28 months old) female Long-Evans rats were used for this study. Five young and five old rats were selected randomly for the current analysis. The young rats used in the current study were also used in a previous method study (Li et al., 2009), including the measurement of the thickness of the myelin sheaths in brain white matter. In this study, the thickness of the myelin sheaths in brain white matter was measured for the first time in aged female rats. The ratio between myelin thickness and the myelinated fiber diameter, and the volume of the myelin sheaths per unit length of myelinated fibers in the white matter was also measured for the first time in young and old female rats. The rats were housed 3-4 per cage and maintained under a constant 12-hrs light/12-hrs dark cycle at an ambient temperature of $22 \pm 1{ }^{\circ} \mathrm{C}$. The colony was certified free from specific pathogens: mouse pneumonia virus, Sendai virus, hepatitis virus, reovirus, lymphocytic choriomeningitis, Theiler murine encephalomyelitis virus, ectromelia, rat minute virus, and Mycoplasma pulmonis. Animal care and treatment followed the guidelines of the National Institutes of Health Guide for the Care and Use of Laboratory Animals (NIH Publications No. 80-23, revised 1996).

\section{SPECIMEN FIXATION AND SAMPLING}

The rats were anesthetized with intraperitoneal injection of $4 \%$ chloral hydrate and perfusion-fixed with solutions of $2 \%$ paraformaldehyde and $2.5 \%$ glutaraldehyde in $0.1 \mathrm{M}$ phosphate-buffered saline ( $\mathrm{pH}$ 7.4). After perfusion, the cerebellum, brain stem and cranial nerves under the pavimentum cerebri were excised, and the cerebral hemispheres were removed. The two hemispheres were embedded in $6 \%$ agar and cut coronally into 2-mm-thick slabs starting at the rostral pole. An average of $10(\mathrm{CV}=0.04)$ slabs were obtained from each hemisphere. The hemispheres (right and left) were selected at random for analysis. A plastic sheet with equidistant points was placed randomly on all the slabs of the sampled hemisphere. Tissue blocks of approximately $1 \mathrm{~mm}^{3}$ were obtained from the white matter at the points where the plastic sheet met the white matter (Li et al., 2008; Yang et al., 2008; Li et al., 2009). Four tissue blocks were obtained per hemisphere. This sampling technique ensured uniform and random distribution of the white matter samples and provided equal sampling probabilities for all parts of the white matter.

\section{TRANSMISSION ELECTRON MICROSCOPY}

The tissue blocks were fixed in a solution containing $4 \%$ glutaraldehyde in a $0.1 \mathrm{M}$ phosphate buffer $(\mathrm{pH}$ 7.4) for at least two hours at $4{ }^{\circ} \mathrm{C}$, rinsed three times in $0.1 \mathrm{M}$ phosphate-buffered saline ( $\mathrm{pH}$ 7.4) and then post-fixed in $1 \% 0.1 \mathrm{M}$ phosphate-buffered osmium tetroxide (pH 7.4) at $4{ }^{\circ} \mathrm{C}$ for two hours. The blocks were gradually dehydrated through a series of $50 \%$, $70 \%$ and $90 \%$ ethanol, a $90 \%$ ethanol and $90 \%$ acetone mixture, and $100 \%$ acetone. The blocks were infiltrated with acetone: resin ratio of $1: 1$ for $3 \mathrm{~h}$ at room temperature, and with absolute resin for $2 \mathrm{~h}$ at $37^{\circ} \mathrm{C}$. The specimens were placed in a mould with a spherical hole $5 \mathrm{~mm}$ in diameter that was then filled with epoxy resin. When the embedding media hardened, spheres containing the specimens were randomly rotated on the table and then re-embedded sequentially at different temperatures for different periods: $37^{\circ} \mathrm{C}(16$ h), $45^{\circ} \mathrm{C}(12 \mathrm{~h})$, and $60^{\circ} \mathrm{C}(14 \mathrm{~h})$. This method, known as the isector method (Nyengaard and Gundersen, 1992), ensures that isotropic, uniform and random (IUR) sections are obtained, and that fiber orientations across all 3 dimensions have an equal probability of being sampled.

One 60-nm-thick section was obtained from each block, stained with uranyl acetate and lead citrate, and viewed using a transmission electron microscope (Hitachi-7500, Hitachi, Ltd., Japan). From each section, 8-12 fields of vision were photographed without bias at a magnification of $x 20,000$.

\section{STEREOLOGICAL ANALYSIS}

\section{White matter volume}

Total white matter volumes of the 2-mm-thick slabs were measured using the Cavalieri principle (Li et al., 
2008; Yang et al., 2008; Li et al., 2009). A transparent counting grid of area $0.39 \mathrm{~mm}^{2}$ associated with each grid point was randomly placed on the caudal surface of each slab. The points in contact with the white matter were counted using an anatomical microscope (Li et al., 2009). The total white matter volume (VWM) was calculated using Cavalieri's equation:

$$
\mathrm{VWM}=\mathrm{t} \times \mathrm{a}(\mathrm{p}) \times \sum \mathrm{PWM},
$$

where $t$ equals slab thickness, $a(p)$ equals area associated with each grid point, and PWM is the total number of grid points in contact with the white matter per rat.

\section{Volume density and total volume of myelin sheaths in the white matter}

The volume density of myelin sheaths in the white matter [VV (ms/wm)] was estimated by placing a transparent counting grid on the photographs (Yang et al., 2008; Li et al., 2009). The points in contact with the white matter; and the points in contact with the myelin sheaths were counted. VV (ms/wm) was estimated as follows:

$$
\mathrm{VV}(\mathrm{ms} / \mathrm{wm})=\sum \mathrm{P}(\mathrm{ms}) / \sum \mathrm{P}(\mathrm{wm}),
$$

where $\sum \mathrm{P}(\mathrm{ms})$ is the total number of points in contact with myelin sheaths in the white matter per rat, and $\sum \mathrm{P}(\mathrm{wm})$ is the total number of points in contact with the white matter per rat. $\sum \mathrm{P}(\mathrm{ms})$ was included in $\sum \mathrm{P}(\mathrm{wm})$. The total volume of myelin sheaths in the white matter $[\mathrm{V}(\mathrm{ms}, \mathrm{wm})]$ was calculated as previously described (Yang et al., 2008; Li et al., 2009):

$$
\mathrm{V}(\mathrm{ms}, \mathrm{wm})=\mathrm{VV}(\mathrm{ms} / \mathrm{wm}) \times \mathrm{V} \mathrm{WM}
$$

\section{Length density and total length of myelinated fibers in white matter}

The length density of myelinated fibers in the white matter $[\mathrm{LV}(\mathrm{mf} / \mathrm{wm})]$ was estimated by randomly overlaying an unbiased counting frame with the actual area of $6,000 \mathrm{~mm}^{2}$ on each photograph (Gundersen, 1977). Myelinated fiber profiles that were completely inside the counting frame or partially inside the counting frame but only touching the top and right lines (i.e., the inclusion lines) were included in the counting, while nerve fiber profiles that touched the left and bottom lines (i.e., the exclusion lines) and their extensions were not counted. LV ( $\mathrm{mf} / \mathrm{wm})$ was calculated according to method previously described (Yang et al., 2008; Li et al., 2009):

$$
\mathrm{LV}(\mathrm{mf} / \mathrm{wm})=2 \times \sum \mathrm{Q}(\mathrm{mf}) /\left[\mathrm{a}(\text { frame }) \times \sum \text { frame }\right],
$$

where 2 is a constant that pertains to IUR sections, $\Sigma \mathrm{Q}(\mathrm{mf})$ is the total number of myelinated fiber profiles counted per rat, a(frame) is the area of one frame, and $\sum$ frame is the total number of counting frames used per rat. The total length of the myelinated fibers in the white matter $[\mathrm{L}(\mathrm{mf}, \mathrm{wm})]$ was estimated as described (Yang et al., 2008; Li et al., 2009):

$$
\mathrm{L}(\mathrm{mf}, \mathrm{wm})=\mathrm{Lv}(\mathrm{mf} / \mathrm{wm}) \times \mathrm{VWM} \text {. }
$$

\section{Diameter of myelinated fibers in white matter}

The external diameter of myelinated fibers [D(mf)] was estimated by measuring the longest profile diameter perpendicular to the longest axis of the myelinated fibers (Yang et al., 2008; Li et al., 2009).

\section{Thickness of the myelin sheath in white matter}

The points of intersection between the axon perimeters and test lines were used to obtain a systematic, uniform, and random sample of locations for direct measurement of myelin sheath thickness in electron micrographs. The orthogonal myelin sheath thickness for each axon ( $t$ ) was estimated as the average of four measurements. The intersections were consecutively numbered; the first position was chosen randomly in the first I/4 interval, the second position was $I / 4+$ position 1 , the third position was $\mathrm{I} / 4+$ position 2 , and the fourth position was $\mathrm{I} / 4+$ position 3 ( $\mathrm{Li}$ et al., 2009). It should be emphasized that the myelin sheath thickness estimates were only valid for the 2-dimensional profiles of the myelinated fibers and not in any simple way reporting the average thickness of the myelin sheaths $[\mathrm{T}(\mathrm{ms})]$ of the real 3-dimensional myelinated fibers.

On every myelinated fiber profiles, which were selected by the unbiased counting frame, the external diameter of myelinated fiber $[\mathrm{D}(\mathrm{mf})]$ and the average thickness of the myelin sheath $[\mathrm{T}(\mathrm{ms})]$ were calculated at the same same. The ratios of the myelin sheath thickness to external diameter of myelinated fiber can be calculated by $\mathrm{T}(\mathrm{ms}) / \mathrm{D}(\mathrm{mf})$.

\section{Tissue shrinkage}

We have measured the tissue shrinkage during the processing in the white matter of young and aged Long-Evans rats, which was $7.5 \%$ and $8.4 \%$, respectively (Yang et al., 2009). The areal shrinkage was not statistically significant. Therefore, the stereological estimates were not corrected for the processing-induced tissue shrinkage. 


\section{STATISTICS}

Variability within groups was estimated using the dimensionless coefficient of variation $(\mathrm{CV}=\mathrm{SD} /$ Mean). Biological coefficient of variation (CVbio) of myelinated fiber length and myelin sheath volume among the brain samples was estimated from the calculated stereological sampling variation (observed coefficient of error, OCE) and observed inter-brain coefficient of variation (OCV), using the relationship:

$$
\begin{gathered}
\mathrm{OCV}^{2}=\mathrm{CVbio}^{2}+\mathrm{OCE}^{2} \\
\text { (Kroustrup and Gundersen, 1983). }
\end{gathered}
$$

The OCE was estimated from the estimated intrabrain coefficient of error using the relationship:

$$
O C E=\sqrt{\text { meanCE }} \text { (West et al., 1991). }
$$

$\mathrm{CE}$ in the Cavalieri estimator of white matter volume, $\mathrm{CE}[\mathrm{V}(\mathrm{WM})]$, in each brain was calculated according to Gundersen et al., (1999). CE [LV(WM)] and $\mathrm{CE}[\mathrm{VV}(\mathrm{WM})]$ were calculated according to the following formula:

$$
\mathrm{CE}_{\mathrm{n}}\left(\frac{\sum \mathrm{Y}}{\sum \mathrm{X}}\right)=\sqrt{\frac{\mathrm{n}}{\mathrm{n}-\mathbf{1}}\left(\frac{\sum(\mathrm{X})^{2}}{\sum \mathrm{X} \sum \mathrm{X}}+\frac{\sum(\mathrm{Y})^{2}}{\sum \mathrm{Y} \Sigma \mathrm{Y}}-\frac{2 \sum(\mathrm{XY})}{\sum \mathrm{X} \sum \mathrm{Y}}\right)}
$$

where $\sum X$ is the number of the fields of vision used in each block when estimating the length density of the myelinated fibers or number of the fields of vision used in each block when estimating the volume density of the myelin sheaths. $\sum \mathrm{Y}$ is the number of myelinated fiber profiles in each block or number of points hitting myelin sheath profiles in each block, and $n$ is the number of blocks used when estimating the length density of myelinated fiber or volume density of myelin sheath in the white matter. The CE in the total length of myelinated fibers, and in total volume of myelin sheaths in each brain sample were estimated from the estimated coefficient of error in the density estimation and the estimated coefficient of error in the white matter volume estimation using the formulae:

$$
\begin{aligned}
& \mathrm{CE}[\mathrm{L}(\mathrm{nf}, \mathrm{wm})]=\sqrt{\left(\mathrm{CE}^{2}[\mathrm{Lv}(\mathbf{n f} / \mathrm{wm})]+\mathrm{CE}^{2}[\mathrm{~V}(\mathrm{wm})]\right)} \\
& \mathrm{CE}[\mathrm{V}(\mathbf{n f}, \mathrm{wm})]=\sqrt{\left(\mathrm{CE}^{2}[\mathrm{Vv}(\mathbf{n f} / \mathrm{wm})]+\mathrm{CE}^{2}[\mathrm{~V}(\mathrm{wm})]\right)} .
\end{aligned}
$$

Statistical analyses were performed with SPSS (version 13.0, SPSS Inc., Chicago, USA). Group means for white matter volumes, total volumes of the myelin sheaths, total lengths of myelinated fibers, volumes of myelin sheaths per unit length of myelinated fibers, and mean thicknesses of myelin sheaths were compared using Student's t test. A threshold significance of $p<$ 0.05 was adopted throughout the analyses.
The diameters of the myelinated fibers were divided into six intervals. In each diameter interval, the thicknesses of the myelin sheaths were divided into six intervals. The total length of the myelinated fibers in each interval (36 intervals) was calculated. The group means for the total length of the myelinated fibers with different myelin sheath thicknesses and different diameters were compared using Mann-Whitney test. A threshold significance of $p<0.05$ was adopted throughout the analyses.

\section{RESULTS}

The stereological estimates of white matter and myelinated fibers in white matter from two groups are presented in Table 1.

\section{WHITE MATTER VOLUME}

Mean white matter volumes were $114.70 \pm 12.14$ $\mathrm{mm}^{3}$ in the young female rats and $68.95 \pm 12.73 \mathrm{~mm}^{3}$ in the old female rats. The total volume of the white matter in the old female rats was decreased by $40.0 \%$ compared with that of the young female rats $(\mathrm{p}<0.01$; Fig. 1A).

\section{CHANGES IN THE MYELIN SHEATHS IN THE WHITE MATTER: VOLUME DENSITY AND TOTAL VOLUME OF THE MYELIN SHEATHS}

The volume densities of myelin sheaths in female rat white matter were $0.29 \pm 0.05$ at 6-8 months, and $0.44 \pm 0.06$ at $27-28$ months. The volume density of the myelin sheaths in old female rats was significantly higher than that in young female rats $(p<0.01)$. The total volume of myelin sheaths in white matter of young female group $\left(33.80 \pm 6.13 \mathrm{~mm}^{3}\right)$ was not significantly different from the total volume of myelin sheaths in the white matter of old female group $\left(30.04 \pm 5.32 \mathrm{~mm}^{3}\right)(\mathrm{p}>0.05$; Fig. 1B).

\section{MYELINATED FIBERS IN THE WHITE MATTER}

There was no significant difference between the mean length density of myelinated fibers in female rat white matter at 6-8 months $\left(0.99 \pm 0.18 \mathrm{~km} / \mathrm{mm}^{3}\right)$ and at $27-28$ months $\left(0.88 \pm 0.29 \mathrm{~km} / \mathrm{mm}^{3}\right)(\mathrm{p}>0.05)$. The total lengths of the myelinated fibers in the female rat white matter were $114.86 \pm 27.86 \mathrm{~km}$ at $6-8$ months and $61.66 \pm 24.95 \mathrm{~km}$ at $27-28$ months. However, mean total length of myelinated fibers in the white matter of the old female rats was significantly decreased by $46.1 \%$ relative to that of the young female rats $(\mathrm{p}<0.05$; Fig. $1 \mathrm{C})$. 


\section{VOLUME OF MYELIN SHEATHS PER UNIT LENGTH OF MYELINATED FIBERS IN THE WHITE MATTER}

Mean volume of myelin sheath per unit length of myelinated fibers in female rats was $0.30 \pm 0.02$ $\mathrm{mm}^{3} / \mathrm{km}$ at $6-8$ months, and $0.53 \pm 0.07 \mathrm{~mm}^{3} / \mathrm{km}$ at 27-28 months. In old, aged female rats, the volume of myelin sheath per unit length of myelinated fibers in the white matter was significantly increased by $43.4 \%$ when compared with that of the young female rats $(\mathrm{p}$ $<0.05$; Fig. 1D).

\section{EXTERNAL DIAMETERS OF MYELINATED FIBERS}

The mean external diameter of myelinated fibers was higher by $17.9 \%$ in the white matter of old female rats than in that of young female rats; however, this increase was not statistically significant $(p>0.05)$.

Table 1. Stereological Estimates of the White Matter, Myelinated Fibers and Myelin Sheaths in the Whiter Matter.

\begin{tabular}{|c|c|c|c|c|c|}
\hline Group & $\mathrm{V}(\mathrm{wm})\left(\mathrm{mm}^{3}\right)$ & $\mathrm{Lv}(\mathrm{mf})\left(\mathrm{km} / \mathrm{mm}^{3}\right)$ & $\mathrm{L}(\mathrm{mf})(\mathrm{km})$ & $\mathrm{Vv}(\mathrm{ms})$ & $\mathrm{V}(\mathrm{ms})\left(\mathrm{mm}^{3}\right)$ \\
\hline \multicolumn{6}{|l|}{ Young } \\
\hline Mean & 114.70 & 0.99 & 114.86 & 0.29 & 33.80 \\
\hline $\mathrm{SD}$ & 12.14 & 0.18 & 27.86 & 0.05 & 6.13 \\
\hline $\mathrm{OCV}(\%)$ & 10.63 & 18.19 & 24.34 & 17.23 & 18.09 \\
\hline $\mathrm{OCE}(\%)$ & 1.64 & 17.38 & 18.77 & 14.37 & 15.38 \\
\hline $\mathrm{OCE}^{2} / \mathrm{OCV}^{2}(\%)$ & 15.42 & 95.54 & 77.11 & 83.40 & 85.06 \\
\hline \multicolumn{6}{|l|}{ Old-aged } \\
\hline Mean & 68.95 & 0.88 & 61.66 & 0.44 & 30.04 \\
\hline $\mathrm{SD}$ & 12.73 & 0.29 & 24.95 & 0.06 & 5.32 \\
\hline $\mathrm{OCV}(\%)$ & 18.49 & 33.04 & 40.48 & 14.54 & 17.74 \\
\hline OCE $(\%)$ & 1.72 & 30.62 & 33.07 & 13.95 & 16.03 \\
\hline $\mathrm{OCE}^{2} / \mathrm{OCV}^{2}(\%)$ & 9.30 & 92.67 & 81.69 & 95.94 & 90.36 \\
\hline
\end{tabular}

$\mathrm{V}(\mathrm{wm})$, mean volume of white matter; Lv (mf), length density of myelinated fibers; L (mf), total length of myelinated fibers; Vv (ms), volume density of myelin sheaths; V(ms), total volume of myelin sheaths. Mean value of each variable (Mean), standard deviation (SD), observed coefficient of variation (OCV), and observed coefficient of error (OCE) are provided. Some of the data for the young rats are from Li et al. (2009). Specifically, the V(wm), L(mf) and V(ms) data are the same as the data in Table 1 of Li et al. (2009).
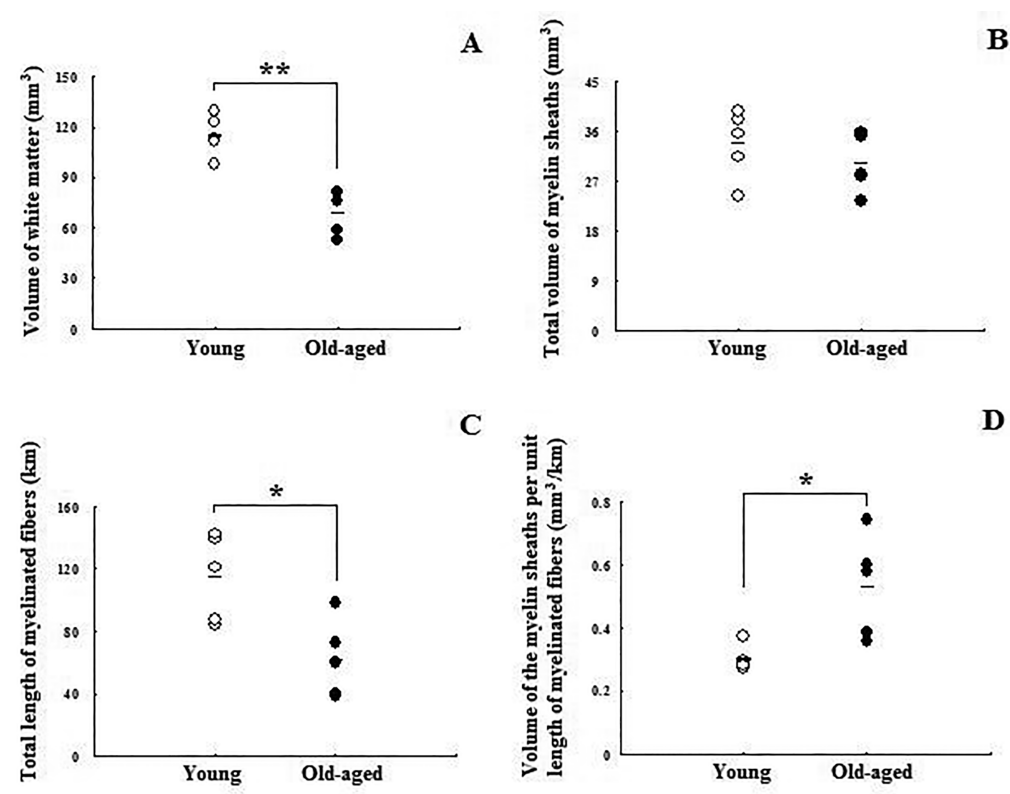

Fig. 1. Comparisons of: white matter volumes of young and old female rats $(A) ;$ total volumes of myelin sheaths in the white matter between young and old female rats $(B)$; total lengths of myelinated fibers in the white matter between the young and old female rats $(C)$; and volumes of myelin sheaths per length of myelinated fiber in the white matter between young and old female rats $(D)$. *indicates $p<0.05$, **indicates $p<0.01$. 


\section{MEAN THICKNESS OF MYELIN SHEATHS}

The mean thicknesses of myelin sheaths in the white matter were $0.12 \pm 0.01 \mu \mathrm{m}$ at $6-8$ months, and $0.18 \pm$ $0.01 \mu \mathrm{m}$ at $27-28$ months. The mean thickness of myelin sheaths in the white matter of the old rats was increased by $33.3 \%$, when compared with that of young female rats $(\mathrm{p}<0.01)$.

\section{MYELINATED FIBER LENGTH WITH DIFFERENT DIAMETERS AND DIFFERENT MYELIN SHEATH THICKNESS}

Results for total length of myelinated fibers with different diameters and different myelin sheath thickness are shown in Fig. 2. Majority of the myelinated fibers had diameters less than $1.0 \mu \mathrm{m}$, and myelin sheath thickness ranging from 0.08 to $0.18 \mu \mathrm{m}$. The total length of myelinated fibers with myelin sheath thickness less than $0.1 \mu \mathrm{m}$ in old-aged female rats was significantly lower when compared to that of young female rats $(\mathrm{p}<0.05$; Fig. 2A). Myelinated fibers with myelin sheath thickness from $0.06 \mu \mathrm{m}$ to $0.1 \mu \mathrm{m}$, and from $0.1 \mu \mathrm{m}$ to $0.14 \mu \mathrm{m}$ in old-aged rats was decreased by $80.7 \%$ and $39.6 \%$, respectively, when compared with corresponding values for young rats ( $<<0.05$; Fig. 2B).

The total length of myelinated fibers with myelin sheath thickness from $0.06 \mu \mathrm{m}$ to $0.1 \mu \mathrm{m}$ ( $\mathrm{p}<0.01)$, and from $0.1 \mu \mathrm{m}$ to $0.14 \mu \mathrm{m}$ in old-aged rats was significantly decreased when compared to that of young rats $(\mathrm{p}<0.05$; Fig. $2 \mathrm{C})$. However, the total length of myelinated fibers with myelin sheath thickness more than $0.22 \mu \mathrm{m}$ in old-aged group was significantly increased when compared to that of young rat group $(\mathrm{p}<0.05$; Fig. $2 \mathrm{C})$. In addition, the total length of myelinated fibers with myelin sheath thickness from $0.06 \mu \mathrm{m}$ to $0.1 \mu \mathrm{m}$, and from $0.1 \mu \mathrm{m}$ to $0.14 \mu \mathrm{m}$ in old-aged rats were significantly decreesed when compared to corresponding values for the young rats $(\mathrm{p}<0.01$; Fig. $2 \mathrm{D})$. Moreover, total length of myelinated fibers with myelin sheath thickness more than $0.22 \mu \mathrm{m}$ in old-aged group was signifycantly increased when compared to that of the young group $(\mathrm{p}<0.05$; Fig. $2 \mathrm{D})$.

However, the total lengths of myelinated fibers with myelin sheath thickness from $0.1 \mu \mathrm{m}$ to 0.14 $\mu \mathrm{m}$, and from $0.14 \mu \mathrm{m}$ to $0.18 \mu \mathrm{m}$ in old-aged rats were significantly decreased when compared to that of young rats $(\mathrm{p}<0.05$; Fig. 2E). Myelinated fiber lengths with myelin sheath thickness more than 0.22 $\mu \mathrm{m}$ in old-aged group was significantly increased when compared to that of the young rats $(p<0.05$; Fig. 2E). The total length of the myelinated fibers with myelin sheath thickness more than $0.22 \mu \mathrm{m}$ in old-aged rat group was increased by $53.5 \%$ when compared with that of young group ( $p>0.05$; Fig. $2 F)$.
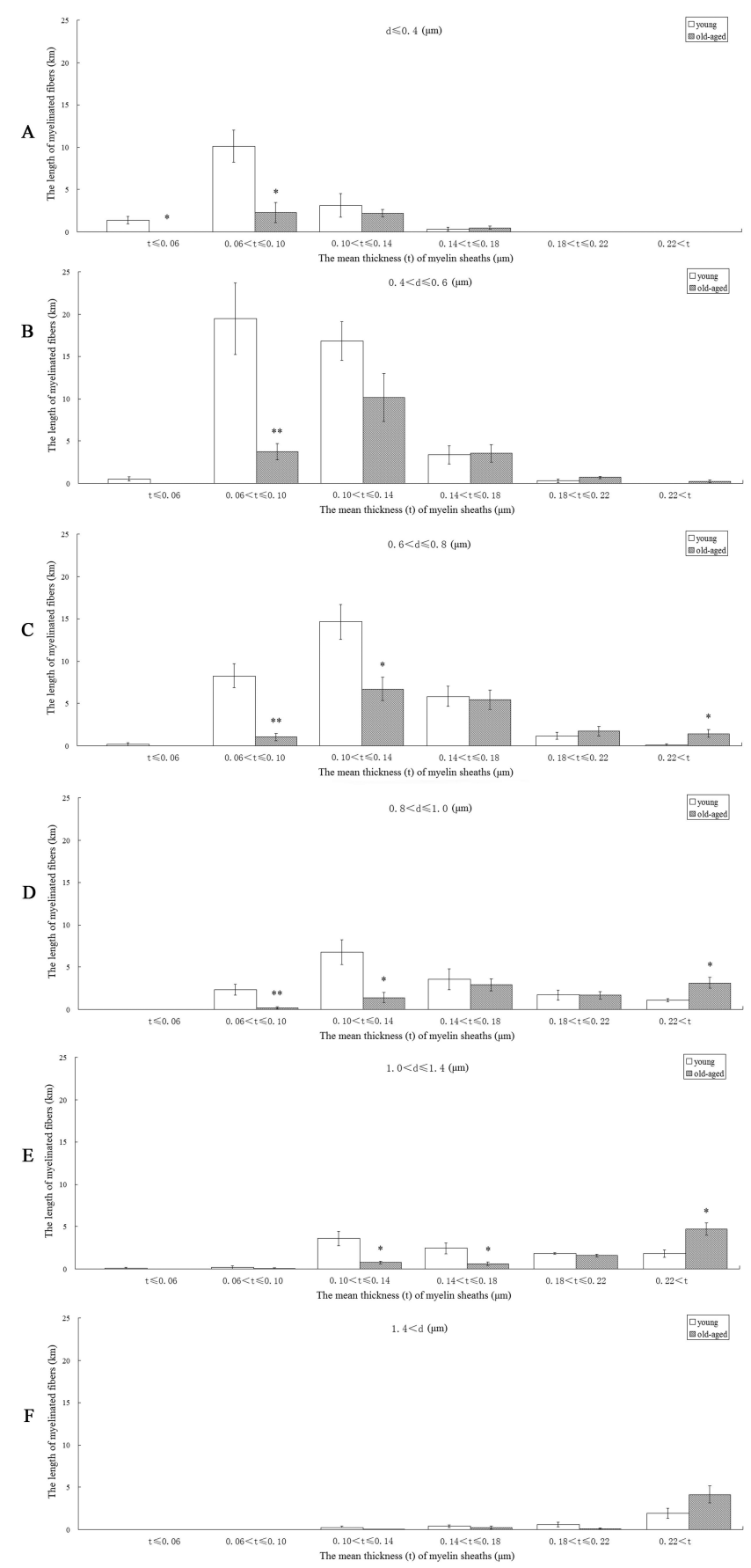

Fig. 2. Total length of myelinated fibers in different intervals of diameter and myelin sheath thickness. $t$ indicates myelin sheath thickness, $d$ indicates myelinated fiber external diameter, *indicates $p<0.05$, $*$ *indicates $p<0.01$. 


\section{ABSOLUTE DISTRIBUTION OF MYELINATED FIBER LENGTH ACCORDING TO RATIOS OF THICKNESS OF MYELIN SHEATH TO EXTERNAL DIAMETER OF MYELINATED FIBER}

The absolute distributions of myelinated fiber length according to the ratios of the myelin sheath thickness to external diameter of myelinated fiber external in the two groups are shown in Fig. 3. Most myelinated fibers in young female rats had ratios of myelin sheath thicknesses to myelinated fiber diameter between 0.12 and 0.28 . However, most myelinated fibers in old, aged female rats had ratios of myelin sheath thicknesses to myelinated fiber diameter between 0.17 and 0.34 . Comparisons of total length of myelinated fibers between young and aged rats clearly showed that the total length of myelinated fibers with ratios less than 0.21 was significantly lower in elderly rats than in young rats. However, the total length of myelinated fibers with ratios of myelin sheath thicknesses to myelinated fiber diameter more than 0.23 was higher in the aged rats than in young rats.

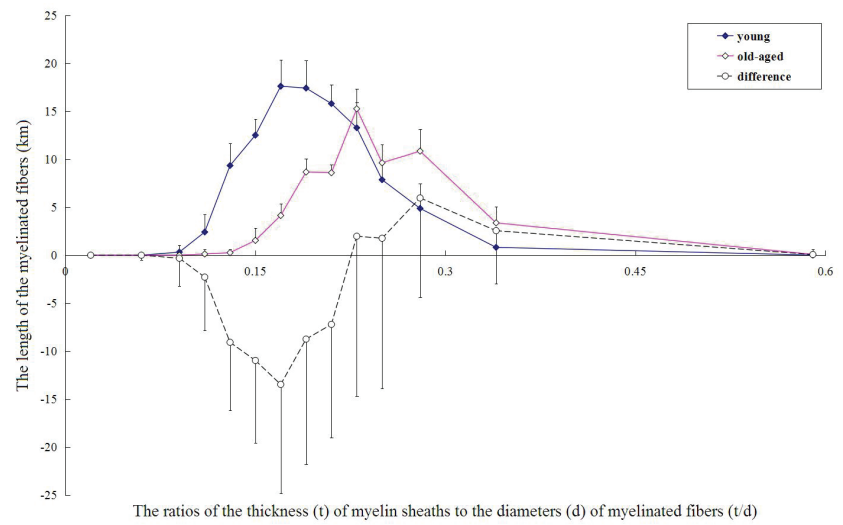

Fig. 3. Absolute distribution of myelinated fiber length according to the ratio of myelin sheath thickness to myelinated fiber diameter.

\section{DISCUSSION}

Alterations in white matter can influence perception, intellectual function, memory, executive function and the speed of motor control (Ylikoski et al., 1993; de Groot et al., 2000; Madureira et al., 2006; Kramer et al., 2007). Based on DTI techniques, white matter tract disruptions have been found to coincide with reduction in age-dependent perception (O'Sullivan et al., 2001; Shenkin et al., 2005). DTI results have indicated that the age-dependence of myelin sheaths in the white matter may lead to disruption of white matter. A sufficient and unbiased stereological method has been established for assessing the myelin sheaths of myelinated fibers in rat brain white matter ( $\mathrm{Li}$ et al., 2009).

In the current study, the results for young and aged rats in Table 1 largely confirmed the results in Table II of Yang et al. (2009). However, Yang et al. (2009) report a statistical decrease of $31 \%$ in the total volume of myelin sheaths with age. We did not find the significant difference as Yang et al. mentioned before. Firstly, it may be because of the sampling error. Six young and nine old female Long-Evans rats were used for this study. Five young and five old rats were selected randomly for the current analysis. We did not use the same animal as Yang et al. used before. Secondly, Yang et al. calculated the points hitting the myelin sheaths on the photos at a magnification of 6,000× (Yang et al., 2009, Fig.2. B). In these magnification photos, sometimes it was hard to identify the calculating point hitting the myelin sheaths. In current study, we used the photos at a magnification of $20,000 \times$. It was easier to identify the myelin sheaths and axons of the myelinated fibers. In current study, the total volume of the myelin sheaths in the white matter of the old female rats was decreased by $11.2 \%$ compared with that of the young female rats. The trend of the changes of the total volume of myelin sheaths in young and old female rats was the same as Yang et al. (2009) mentioned before. In addition, the total length of myelinated fibers in the old female rats was significantly decreased by $46.1 \%$ compared with that of the young female rats. The myelin sheath volume per unit length of the myelinated fibers in the white matter of the old female rats was significantly increased by $43.4 \%$ compared with that of the young female rats. It is very likely that the age-related loss of myelinated fibers in the white matter occurred mostly in myelinated fibers with thinner myelin sheaths. Myelinated fibers in the white matter with thicker myelin sheaths may be more easily preserved during the aging process. The age-related loss of the myelinated fibers with thinner myelin sheaths, together with the preservation of the myelinated fibers with thicker myelin sheaths, may explain our current results. In this study, we calculated the length of the myelinated fibers with different diameters and different myelin sheath thicknesses, and found that most of age-related losses occurred in myelinated fibers with diameters less than $1.4 \mu \mathrm{m}$ and the myelin sheaths thicknesses less than $0.14 \mu \mathrm{m}$. There were no significant agerelated decreases in the length of myelinated fibers with large diameters and thicker myelin sheaths. Moreover, from absolute distributions of myelinated 
fiber length according to ratios of myelin sheath thicknesses to myelinated fibers external diameter, the total length of myelinated fibers with ratios less than 0.21 was significantly lower in the aged rats than in young rats. Therefore, the current findings confirm agerelated loss of myelinated fibers with thinner myelin sheaths, together with the preservation of myelinated fibers with thicker myelin sheaths. This may explain why the total length of the myelinated fibers significantly decreased with age but the total volume of the myelin sheaths did not decrease with age, and why the myelin sheath volume per unit length of myelinated fibers did increase with age.

It was also observed that the length of myelinated fibers with diameters more than $0.6 \mu \mathrm{m}$, and myelin sheath thicknesses more than $0.22 \mu \mathrm{m}$ increased with age. It is interesting to discover that myelinated fibers with large diameters and thicker myelin sheaths increased with age. In previous studies on aged monkey brains, two of the age-related alterations seen in this study in myelin sheaths (local splitting of the major dense lines and the formation of myelin balloons) were observed in the anterior commissure, primary visual cortex and corpus callosum (Peters et al., 2000; 2001; Peters and Sethares, 2002; Sandell and Peters, 2003). Moreover, it has been reported that myelin sheath changes were also involved in various diseases (Lassmann et al., 1997; Myers, 1998; Biffiger et al., 2000), and in various experimental conditions (Blakemore, 1978; Chang, 1990; Anderson et al., 1998; Franco-Pons et al., 2007; Karim et al., 2007; Skripuletz et al., 2008;). Similar age-related changes in the myelin sheaths of elderly rats were observed in this study (Fig.4A, Fig.4B). Indeed, approximately $6.58 \%$ myelin sheath profiles showed these degenerative alterations. These degenerative alterations in the aged rat brain might either loosen the originally compacted myelin sheaths or increase the thickness of myelin sheaths.

Other investigators have reported shortened internodal lengths, formation of large sheaths and formation of double sheaths in aged monkey brains (Peters et al., 2000; 2001; Peters and Sethares, 2003). These findings may be evidence of re-myelination. Therefore, these investigators concluded that re-myelination concomitant with de-myelination occurs in the primate central nervous system during aging. In the present study, we also observed formation of large sheaths in the white matter of the old rats (Fig. 4C), and approximately $0.88 \%$ myelin sheath profiles showed this regenerative alteration. These regenerative alterations of myelin sheaths in the white matter of the aged brain may increase the external diameter of the myelinated fibers and the total volume of the myelin sheaths. Therefore, the age-related degenerative changes in the myelin sheaths in combination with age-related remyelination may explain why the myelinated fibers in white matter with large diameters and thicker myelin sheaths increased with age. The changes also account for the significant increases in the value of myelin sheath volume per unit length of the myelinated fibers in the white matter of the old rats.
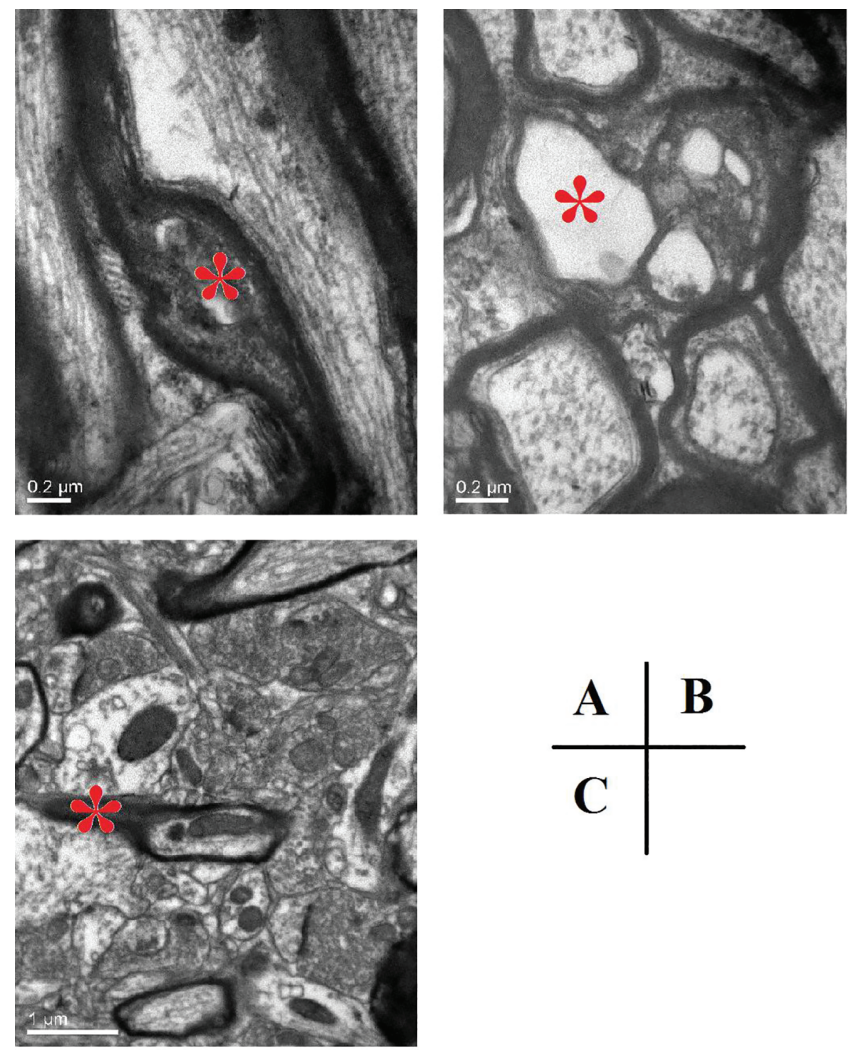

Fig. 4. Alteration of the myelin sheaths in the aged rats. * indicates the local splitting of the major dense lines (A); the formation of myelin balloons (B); the formation of large sheaths $(C)$.

Myelin sheaths facilitate fast conduction of action potentials down axons. Changes in the fine structure of myelin in a neural circuit, such as alterations in sheath thickness and internode length, are expected to affect conduction velocity (Purger et al., 2016). Myelinated fibers with large diameters and thick myelin sheaths can produce more effective conduction velocities. In this study, the mean diameter of myelinated fibers and mean thickness of myelin sheaths in aged rats were much higher than in young rats. Although myelinated fibers with large diameters and thick myelin sheaths in elderly rats were intact, the total length of the myelinated fibers in the aged rats was significantly decreased. The loss of myelinated fibers could induce decreases in conduction velocity. Degenerations and regenerations of myelin sheaths, as we 
showed before, could increase the diameters of myelinated fibers and the thickness of myelin sheaths. However, degenerations and regenerations of myelin sheaths do not increase but rather decrease conduction velocity (Peters et al., 2000; 2001; Peters and Sethares, 2003). Therefore, although the mean diameter of myelinated fibers and mean thickness of myelin sheaths in elderly rats were much higher than in the young rats, conduction velocity in the old rats might be lower than in the young rats. This age-dependent reduction in conduction velocity may induce age-dependent reduction in perception.

\section{STUDY LIMITATION}

One limitation in this study is that in young and aged rat groups, the mean OCEs for most parameters were greater than the recommended value, that is, less than $10 \%$. For most parameters, the stereological sampling variance $\left(\mathrm{OCE}^{2}\right)$ constituted more than $50 \%$ of the total observed variance $\left(\mathrm{OCV}^{2}\right)$. Considering the relatively high stereological sampling variation, more blocks and counting fields need to be sampled from each rat white matter in future studies.

\section{CONCLUSION}

This research has provided stereological evidence not only for the degeneration of myelin sheaths of smalller axons, but also for the regeneration of myelin sheaths in larger axons in aged white matter. This agedependent degeneration and regeneration of myelin sheaths may induce reduction in velocity of conduction of action potentials, as well as reduction in age-dependent perception.

\section{ACKNOWLEDGMENTS}

This study was supported by Youth Science Foundation (YJ(QN)201307) and Key Project (YJ(ZD)201404) of the Second Affiliated Hospital of Xi'an Jiaotong University, Youth Science Foundation of Xi'an Jiaotong University (xjj2014082), Natural Science Foundation of Shaanxi Government (2015JQ8319).

\section{REFERENCES}

Anderson TJ, Schneider A, Barrie JA, Klugmann M, McCulloch MC, Kirkham D, et al. (1998). Late-onset neurodegeneration in mice with increased dosage of the proteolipid protein gene. J Comp Neurol 394:506-19.

Biffiger K, Bartsch S, Montag D, Aguzzi A, Schachner M, Bartsch U (2000). Severe hypomyelination of the Murine CNS in the Absence of Myelin-Associated Glycoprotein and Fyn Tyrosine Kinase. J. Neurosci 20:7430-7.
Blakemore WF (1978). Observations on remyelination in the rabbit spinal cord following demyelination induced by lysolecithin. Neuropathol Appl Neurobiol 4:47-59.

Chang LW (1990). The neurotoxicology and pathology of organomercury, organolead and organotin. J Toxicol Sci Suppl 4:125-51.

de Groot JC, de Leeuw FE, Oudkerk M, van Gijn J, Hofman A, Jolles J, et al. (2000). Cerebral white matter lesions and cognitive function: the Rotterdam Scan Study. Ann Neurol 47:145-51.

Del Bigio MR, Wilson MJ, Enno T (2003). Chronic hydrocephalus in rats and humans: white matter loss and behavior changes. Ann Neurol 53:337-46.

Franco-Pons N, Torrente M, Colomina MT, Vilella E (2007). Behavioral deficits in the cuprizone-induced murine model of demyelination/remyelination. Toxicol Lett 169:205-13

Gundersen HJG (1977). Notes on the estimation of the numerical density of arbitrary particles: The edge effect. $J$ Microsc 111:219-23.

Gundersen HJG, Bendtsen TF, Korbo L, Marcussen N, M $\varphi$ ller A, Nielsen K, et al. (1988a). Some new, simple and efficient stereological methods and their use in pathological research and diagnosis. AMPIS 96:379-94.

Gundersen HJG, Bagger P, Bendtsen TF, Evans SM, Korbo L, Marcussen N, et al. (1988b). The new stereological tools: Disector, fractionator, nucleator and point sampled intercepts and their use in pathological research and diagnosis. APMIS 96:857-81.

Gundersen HJG, Jensen EB, Kiêu K, Nielsen J (1999). The efficiency of systematic sampling in stereology-reconsidered. J Microsc 193:199-211.

Guttmann CR, Jolesz FA, Kikinis R, Killiany RJ, Moss MB, Sandor T, et al. (1998). White matter changes with normal aging. Neurology 50:972-8.

Huang J, Auchus AP (2007). Diffusion tensor imaging of normal appearing white matter and its correlation with cognitive functioning in mild cognitive impairment and Alzheimer's disease. Ann N Y Acad Sci 1097: 259-64.

Jernigan TL, Archibald SL, Fennema-Notestine C, Gamst AC, Stout JC, Bonner J, et al. (2001). Effects of age on tissues and regions of the cerebrum and cerebellum. Neurobiol Aging 22:81-94.

Karim SA, Barrie JA, McCulloch MC, Montague P, Edgar JM, Kirkham D, et al. (2007). PLP overexpression perturbs myelin protein composition and myelination in a mouse model of Pelizaeus-Merzbacher disease. Glia 55:341-51.

Kemper TL (1994). Neuroanatomical and neuropathological changes during aging and dementia. In: Albert ML, Knoefel JE, editors. Clinical neurology of aging. New York: Oxford University Press, pp. 3-67.

Kramer JH, Mungas D, Reed BR, Wetzel ME, Burnett MM, Miller BL, et al. (2007). Longitudinal MRI and cogni- 
tive change in healthy elderly. Neuropsychology 21: 412-8.

Kroustrup JP, Gundersen HJ (1983). Sampling problems in an heterogeneous organ: quantitation of relative and total volume of pancreatic islets by light microscopy. J Microsc 132:43-55.

Lassmann H, Bartsch U, Montag D, Schachner M (1997). Dying-back oligodendrogliopathy: a late sequel of myelin-associated glycoprotein deficiency. Glia 19: 104-10.

Li C, Yang S, Zhang W, Shi X, Wang W, Nyengaard JR, Tang Y (2008). Unbiased stereological quantification of unmyelinated fibers in the rat brain white matter. Neurosci Lett 437:38-41.

Li C, Yang S, Chen L, Lu W, Qiu X, Gundersen HJG, et al. (2009). Stereological methods for estimating the myelin sheaths of the myelinated fibers in white matter. Anat Rec 292:1648-55.

Madureira S, Verdelho A, Ferro J, Basile AM, Chabriat H, Erkinjuntti T, et al. (2006). Development of a neuropsychological battery for the Leukoaraiosis and Disability in the Elderly Study (LADIS): experience and baseline data. Neuroepidemiology 27:101-16.

Moller A, Strange P, Gundersen HJ (1990). Efficient estimation of cell volume and number using the nucleator and the disector. J Microsc 159:61-71.

Myers SF (1998). Myelin-sheath abnormalities in the vestibular nerves of chronically diabetic rats. Otolaryngol Head Neck Surg 119:432-8.

Nagy Z, Westerberg H, Klingberg T (2004). Maturation of white matter is associated with the development of cognitive functions during childhood. J Cogn Neurosci $16: 1227-33$

Nyenggard JR, Gundersen HJG (1992). The isector: a simple and direct method for generating isotropic, uniform random sections from small specimens. J Microsc 165: 427-31.

O'Sullivan M, Jones DK, Summers PE, Morris RG, Williams SC, Markus HS (2001). Evidence for cortical "disconnection" as a mechanism of age-related cognitive decline. Neurology 57:632-8.

Purger D, Gibson EM, Monje M (2016). Myelin plasticity in the central nervous system. Neuropharmacology 110:563-73.

Pakkenberg B, Gundersen HJG (1997). Neocortical neuron number in humans: effect of sex and age. J Comp Neurol 384:312-20.

Peters A (2002). Structural changes in the normally aging cerebral cortex of primates. Prog Brain Res 136:455-65.
Peters A, Josephson K, Vincent SL (1991). Effects of aging on the neuroglial cells and pericytes within area 17 of the rhesus monkey cerebral cortex. J Comp Neurol 299: 384-98.

Peters A, Moss MB, Sethares C (2000). Effects of aging on myelinated nerve fibers in monkey primary visual cortex. J Comp Neurol 419:364-76.

Peters A, Rosene DL, Moss MB, Kemper TL, Abraham CR, Tigges J, et al. (1996). Neurobiological bases of age-related cognitive decline in the rhesus monkey. J Neuropathol Exp Neurol 55:861-74.

Peters A, Sethares C, Killiany RJ (2001). Effects of age on the thickness of myelin sheaths in monkey primary visual cortex. J Comp Neurol 435:241-8.

Peters A, Sethares C (2002). Aging and the myelinated fibers in prefrontal cortex and corpus callosum of the monkey. J Comp Neurol 442:277-91.

Peters A, Sethares C (2003). Is there remyelination during aging of the primate central nervous system? J Comp Neurol 460:238-54.

Sandell JH, Peters A (2003). Disrupted myelin and axon loss in the anterior commissure of the aged rhesus monkey. J Comp Neurol 466:14-30.

Shenkin SD, Bastin ME, Macgillivray TJ, Deary IJ, Starr JM, Rivers CS, et al. (2005). Cognitive correlates of cerebral white matter lesions and water diffusion tensor parameters in community-dwelling older people. Cerebrovasc Dis 20:310-8.

Skripuletz T, Lindner M, Kotsiari A, Garde N, Fokuhl J, Linsmeier F, et al. (2008). Cortical demyelination is prominent in the murine cuprizone model and is straindependent. Am J Pathol 172:1053-61.

Sterio DC (1984). The unbiased estimation of number and sizes of arbitrary particles using the disector. J Microsc 134:127-36.

West MJ, Slomianka L, Gundersen HJ (1991). Unbiased stereological estimation of the total number of neurons in thesubdivisions of the rat hippocampus using the optical fractionator. Anat Rec 231:482-97.

Yang S, Li S, Zhang W, Wang WW, Nyengaard JR, Tang Y (2008). Application of stereological methods to study the white matter and myelinated fibers therein of rat brain. Image Anal Stereol 27:125-32.

Yang S, Li C, Lu W, Zhang W, Wang WW, Tang Y (2009). The myelinated fiber changes in the white matter of aged female Long-Evans rats. J Neurosci Res 87:1582-90.

Ylikoski R, Ylikoski A, Erkinjuntti T, Sulkava R, Raininko $\mathrm{R}$, Tilvis $\mathrm{R}$ (1993). White matter changes in healthy elderly persons correlate with attention and speed of mental processing. Arch Neurol 50:818-24. 